\title{
Characterizing pre-dialysis care in the era of eGFR reporting: a cohort study
}

Khaled Abdel-Kader ${ }^{1 *}$, Gary S Fischer², James R Johnston ${ }^{1}$, Chen Gu², Charity G Moore², Mark L Unruh

\begin{abstract}
Background: Chronic kidney disease (CKD) is a common disorder associated with increased morbidity and mortality. Primary care physicians (PCPs) care for the majority of pre-dialysis CKD patients; however, PCPs often do not recognize the presence of CKD based on serum creatinine levels. Prior studies suggest that PCPs and nephrologists deliver suboptimal CKD care. One strategy to improve disease awareness and treatment is estimated glomerular filtration rate (eGFR) reporting. We examined PCP and nephrologist CKD practices before and after routine eGFR reporting.
\end{abstract}

Methods: We conducted a retrospective cohort study of patients with CKD 3b-4 (eGFR < 45) seen at a universitybased, outpatient primary care clinic. Using a chi-square or Fisher's exact test, we compared co-management rates, renal protective strategies, CKD documentation, and laboratory processes of care in 274 patients and 266 patients seen in a 6-month period prior to and following eGFR implementation, respectively.

Results: CKD co-management increased from 22.6\% pre-eGFR to 48.5\% post-eGFR ( $P<0.0001$ ). eGFR reporting did not improve angiotensin converting enzyme inhibitor or angiotensin receptor blocker use or quantitative urinary testing. However, non-steroidal anti-inflammatory drug avoidance (pre-eGFR $81.8 \%$ vs. post- eGFR 90.6\%, P = 0.003) and phosphorus and parathyroid hormone testing improved (pre-eGFR vs. post-eGFR: $32.5 \%$ vs. $51.5 \%, P<0.0001$; $12.4 \%$ vs. $36.1 \%, P<0.0001$ respectively).

Conclusions: A marked increase in CKD co-management was observed following eGFR implementation. Although some improvements in processes of care were noted, this did not include angiotensin converting enzyme inhibitor or angiotensin receptor blocker use. Overall care remained suboptimal despite eGFR reporting; further strategies are needed to improve PCP and nephrologist CKD care.

\section{Background}

Over 12 million adults in the United States (US) have chronic kidney disease (CKD) stage 3 or greater (estimated glomerular filtration rate $<60 \mathrm{ml} / \mathrm{min} / 1.73 \mathrm{~m}^{2}$ ) [1]. Further, the prevalence of CKD appears to be rising [1] and with the increasing incidence of obesity, diabetes, and hypertension [2-6], this trend is expected to continue. Presently, primary care physicians (PCPs) deliver most of the care to patients with non-dialysis dependent CKD [7-10]. However, PCPs may not recognize the presence of CKD and as many as $66 \%$ of PCPs may be unaware of Kidney Disease Outcome Quality Initiative (K/DOQI) clinical practice guidelines [11]. Given that CKD progression and its associated morbidity and mortality can be reduced with

\footnotetext{
* Correspondence: abdelkaderk@upmc.edu

${ }^{1}$ Renal-Electrolyte Division, University of Pittsburgh, Pittsburgh, USA

Full list of author information is available at the end of the article
}

optimal care $[12,13]$, late detection and treatment contributes to poor patient outcomes [14]. Among the approaches advocated for the improvement of CKD outcomes are optimization of care by increasing disease awareness and adherence to CKD clinical practice guidelines including angiotensin converting enzyme inhibitor (ACEI) or angiotensin receptor blocker (ARB) use and timely renal referrals.

One important development in the ongoing effort to improve CKD recognition is the implementation of routine eGFR reporting. Although imperfect, eGFR values account for demographic factors that are important determinants of muscle mass and serum creatinine levels and provide physicians with more accurate estimates of kidney function than isolated serum creatinines [15]. The National Kidney Foundation has advocated for the use of prediction equations to estimate kidney function [16] and

\section{() Biomed Central}


the most widely used equation is presently the 4-variable Modification of Diet in Renal Disease (MDRD) Study equation [17-21]. The routine reporting of eGFR values with serum creatinine has been advocated by some experts as an important approach to improve CKD awareness and treatment [22-24] and recent data reveal that an increasing number of US labs are adopting universal eGFR reporting [21,25]. Multiple studies have documented the effect of routine eGFR reporting on renal referrals [8,26-28]; however, few studies have examined the quality of care delivered to CKD patients since the implementation of eGFR reporting [28-30]. In addition, despite previously well-documented deficiencies in nephrologist care of CKD patients [10,31-35], few studies have examined whether there have been improvements in the care of co-managed CKD patients following eGFR reporting.

In this report, we examine the care of patients with advanced CKD (stages 3b-4) before and after routine eGFR reporting at an academic, hospital-based primary care (general internal medicine [GIM]) practice. In addition, we examine the care of advanced CKD patients solely managed by their PCPs (hereafter referred to as PCP managed) or co-managed with a nephrologist (hereafter referred to as co-managed) before and after routine eGFR reporting. We hypothesized that following routine eGFR implementation there would be modest improvements in care for PCP managed patients but no improvements in care for co-managed patients. We also hypothesized that co-managed CKD patients would have better kidney-disease specific processes of care compared to PCP managed patients.

\section{Methods}

\section{Study population and setting}

We conducted a retrospective review of University of Pittsburgh Medical Center outpatients cared for at a hospital-based primary care (i.e., GIM) clinic prior to and following routine laboratory implementation of eGFR reporting that began in October 2005. The study inclusion criteria were age $\geq 18$ years, the presence of at least one automated or investigator-calculated eGFR value of $<45 \mathrm{ml} / \mathrm{min} / 1.73 \mathrm{~m}^{2}$, and an outpatient visit with a university GIM PCP either during the 6-months immediately prior to local laboratory eGFR reporting (pre-eGFR cohort 4/1/05-9/30/05) or during 6-months after local eGFR reporting had become routine (posteGFR cohort 12/1/07-5/31/08, Figure 1). We chose a more recent 6 -month post-eGFR period to allow the measure to gain wider acceptance and to give providers the opportunity to acclimate to its use. Participants were excluded for the following reasons: prior kidney transplant, any form of renal replacement therapy, CKD stage $5\left(\mathrm{eGFR}<15 \mathrm{ml} / \mathrm{min} / 1.73 \mathrm{~m}^{2}\right)$, or any automated

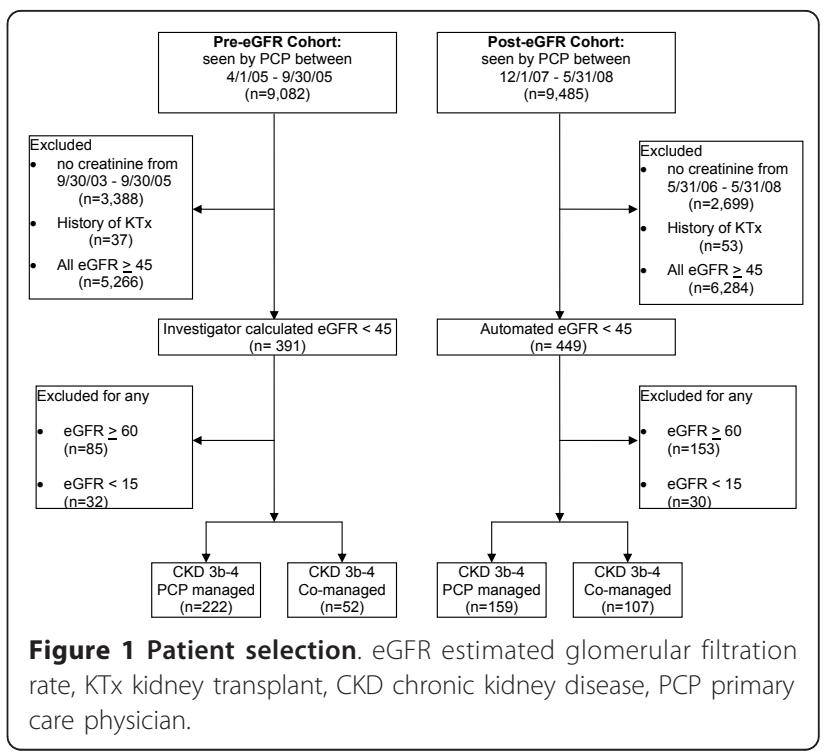

or investigator calculated eGFR $\geq 60 \mathrm{ml} / \mathrm{min} / 1.73 \mathrm{~m}^{2}$. The University of Pittsburgh Institutional Review Board approved this study.

\section{Data collection}

\section{Creatinine/eGFR ascertainment and reporting}

For all eligible participants, all creatinine and eGFR values were abstracted from the electronic medical record (EMR). For the pre-eGFR cohort, all serum creatinine values from 9/30/03 - 9/30/05 were abstracted. For the post-eGFR cohort, all eGFR and serum creatinine values from 5/31/06 - 5/31/08 were abstracted. Non-calibrated, modified Jaffe serum creatinine assays were used by the local university laboratory during both study periods. The 4-variable MDRD study equation [18] was used by either the study investigators or the local laboratory to calculate eGFR values for the preeGFR cohort and the post-eGFR cohort, respectively.

For all patients with a laboratory reported eGFR, the following message accompanied their eGFR results, "eGFR $<60 \mathrm{~mL} / \mathrm{min} / 1.73 \mathrm{~m}^{2}$ indicates kidney disease. eGFR $<15 \mathrm{~mL} / \mathrm{min} / 1.73 \mathrm{~m}^{2}$ indicates kidney failure." No systematic educational activities regarding eGFR reporting were undertaken at the university hospital prior to or following eGFR implementation as of $5 / 31$ / 2008.

\section{Outcomes}

The primary outcome was referral to a nephrologist determined by the presence of an EMR order for a nephrology consultation (regardless of whether the patient kept the appointment) or the presence of a nephrology encounter in the EMR during the six month cohort period or within 2 months of the end of each respective cohort period. This 2 -month delay allowed 
time for patients evaluated at the end of the 6-month period to have laboratory tests completed and further orders placed (e.g., specialist referral) as deemed appropriate by the PCP.

Secondary outcomes included CKD documentation, ACEI or ARB use, non-steroidal anti-inflammatory drug (NSAID) use, urinary albumin quantification, and lab monitoring of hemoglobin (Hgb), phosphorus, and parathyroid hormone (PTH) levels. We also intended to assess serum calcium monitoring; however, in early 2006 serum calcium was included in the laboratory's basic metabolic profile confounding any possible pre-eGFR versus posteGFR comparisons. CKD documentation was determined by the presence of an International Classification of Disease, Ninth Revision (ICD-9) code on the patient's EMR problem list or as a billing diagnosis in a PCP outpatient encounter. These codes included: 249.4( $\times$ ), 250.4( $\times$ ), 403.

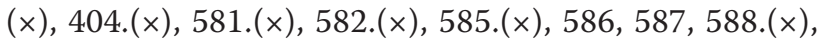
$593.7 \times, 753.13,753.14$, and 794.4. Use of an ACEI/ARB was determined by the presence of an ACEI/ARB on the patient's EMR medication list at the end of each cohort period. The EMR medication list automatically updates based on electronic prescriptions or medications entered for documentation purposes. Use of an NSAID was determined by the presence of an NSAID on the patient's EMR medication list at the end of each respective cohort period. Urinary albumin quantification was determined by the presence of an EMR order or laboratory value for a random, quantitative spot assessment for albuminuria in the prior 12 months. Lab testing for Hgb, phosphorus, and PTH was determined by the presence of an EMR order or laboratory value for each respective test within the prior 12 months.

\section{Covariates}

We abstracted the following covariates from the EMR on all eligible patients: age, sex, race (self-reported), insurance status, diagnosis of diabetes, diagnosis of hypertension, and baseline co-management status (i.e., baseline renal referral status). Insurance status was categorized as private, Medicare, medical assistance/Medicaid, or selfpay. Diabetes and hypertension were determined by the presence of the disease on the patient's EMR problem list or as a billing diagnosis in a PCP outpatient encounter in the 12 months preceding the end of each cohort period. Baseline co-management status was determined by the presence of any EMR outpatient encounter with a nephrologist during the 24 months preceding each cohort period. A simple random sample was used to select $10 \%$ of patient charts for an EMR chart audit to verify the accuracy of abstracted data.

\section{Statistical analyses}

Differences between the groups in demographic characteristics and clinical variables were assessed using a
Student's $t$-test or analysis of variance for continuous variables and a chi-square or Fisher's exact test for categorical variables. Differences in clinical care (nephrology referral, CKD documentation, ACEI/ARB use, etc) were assessed using a chi-square or Fisher's exact test for categorical variables. For the primary outcome (nephrology referral), associations with demographic and clinical variables were assessed in the pre- and post-eGFR cohorts using a chi-square test. Multivariable associations between the dependent variable, co-management status, and demographic and clinical variables were examined in each cohort using a logistic regression model. Model selection was based on variables that were found to have an association $(\mathrm{P}<0.2)$ in univariate analyses. Final model variables were age, sex, race, insurance status, diabetic status, and creatinine. For all analyses, $\mathrm{P}$ values $<0.05$ were considered significant. Analyses were performed using SAS version 9.1 (Cary, NC).

\section{Results}

\section{Baseline characteristics}

In the pre-eGFR cohort, 391 eligible patients had an eGFR $<45 \mathrm{ml} / \mathrm{min} / 1.73 \mathrm{~m}^{2}$ (Figure 1). Just over $79 \%$ of these patients had 2 or more serum creatinine measurements. In the post-eGFR cohort, 449 eligible patients had an eGFR $<45 \mathrm{ml} / \mathrm{min} / 1.73 \mathrm{~m}^{2}$ (Figure 1). Over $94 \%$ had 2 or more serum creatinine measurements. After excluding patients with any eGFR $<15 \mathrm{ml} / \mathrm{min} / 1.73 \mathrm{~m}^{2}$ or $\geq 60 \mathrm{ml} / \mathrm{min} / 1.73 \mathrm{~m}^{2}, 274$ and 266 patients remained in the pre-eGFR and post-eGFR cohorts, respectively (Figure 1).

Patients in the post-eGFR cohort were more likely to be male, African-American, and have hypertension documented in the EMR than pre-eGFR patients (Table 1). Additionally, post-eGFR patients were more likely to have private insurance and less likely to have Medicare; they also had higher serum creatinines and modestly lower eGFR values (Table 1).

When examining patients stratified by eGFR cohort and referral status (Table 2), PCP managed patients in the pre-eGFR cohort were older, less likely to be African-American, less likely to have hypertension documented in the EMR, less likely to have private insurance and more likely to have Medicare than PCP managed patients in the post-eGFR cohort. PCP managed patients in the pre-eGFR cohort also had modestly lower serum creatinines and higher eGFR values than PCP managed post-eGFR patients.

Co-managed patients in the pre-eGFR cohort were less likely to have hypertension documented in the EMR than co-managed post-eGFR patients (Table 2).

Pre-eGFR PCP managed patients were significantly older than pre-eGFR co-managed patients (Table 2). In addition, PCP managed patients had lower serum 
Table 1 Baseline characteristics

\begin{tabular}{lccl}
\hline & $\begin{array}{c}\text { Pre-eGFR } \\
(\mathbf{n}=\mathbf{2 7 4})\end{array}$ & $\begin{array}{c}\text { Post-eGFR } \\
(\mathbf{n}=\mathbf{2 6 6})\end{array}$ & P-Value* $^{*}$ \\
\hline Age $($ years $)$ & $70.5(13.7)$ & $68.7(13.4)$ & 0.12 \\
\hline Female & $70.8 \%(194)$ & $60.9 \%(162)$ & 0.02 \\
\hline African-American & $23.7 \%(65)$ & $38.3 \%(102)$ & 0.0002 \\
\hline Diabetes & $31.8 \%(87)$ & $36.8 \%(98)$ & 0.21 \\
\hline Hypertension & $63.1 \%(173)$ & $79.7 \%(212)$ & $<0.0001$ \\
\hline Insurance Status & & & \\
\hline \multicolumn{1}{c}{ Private } & $32.5 \%(89)$ & $46.6 \%(124)$ & 0.002 \\
\hline Medicare & $56.6 \%(155)$ & $45.9 \%(122)$ & \\
\hline \multicolumn{1}{c}{ Medical Assistance } & $5.5 \%(15)$ & $5.6 \%(15)$ & \\
\hline Self-pay & $5.5 \%(15)$ & $1.9 \%(5)$ & \\
\hline eGFR $\left(\mathrm{ml} / \mathrm{min} / 1.73 \mathrm{~m}^{2}\right)$ & $36.1(7.1)^{* *}$ & $33.7(7.9)^{\ddagger}$ & 0.0002 \\
\hline Creatinine $(\mathrm{mg} / \mathrm{dl})$ & $1.80(0.52)^{* *}$ & $1.97(0.72)^{\ddagger}$ & 0.002 \\
\hline
\end{tabular}

Continuous variables are presented as means with standard deviations. Categorical variables are expressed as percentages and frequencies.

*Students t-test, chi-square, or Fisher's exact test used as appropriate. eGFR estimated glomerular filtration rate.

creatinines and higher eGFR values than co-managed patients regardless of their eGFR cohort.

\section{Renal referrals and co-management}

The overall prevalence of CKD 3b-4 co-management increased significantly from the end of the pre-eGFR cohort $(22.6 \%)$ to the end of the post-eGFR cohort $(48.5 \%, \mathrm{P}<0.0001 ;$ Figure 2$)$. Differences in the prevalence of co-managed patients were apparent in both the CKD 3b and CKD 4 subgroups (Figure 2). In addition, a smaller proportion of PCP managed patients were newly referred during the 8 month study/follow-up period in the pre-eGFR cohort versus the post-eGFR cohort; however, the absolute percentage of patients newly referred was modest in both arms (pre-eGFR $4.5 \%$ vs. post-eGFR $13.8 \%, \mathrm{P}=0.001$ ). The percentage of patients newly referred to a nephrologist during the study period was mildly higher when examining the CKD 4 subgroup (pre-eGFR 9.4\% [n = 32] vs. posteGFR $25.8 \%$ [ $\mathrm{n}=31$ ], $\mathrm{P}=0.09$ ). Excluding all patients with a single creatinine value did not substantially alter our findings. Examining only patients with 3 or more serum creatinine values did not qualitatively alter our findings although a modest increase in co-management was noted in both the pre-eGFR and post-eGFR groups.

We examined univariate associations with renal referral status at the end of each cohort period. In the pre-eGFR cohort, age $<70$ (35\% vs. $15 \%, \mathrm{P}<0.0001)$, AfricanAmerican race ( $34 \%$ vs. $19 \%, P=0.01$ ), and CKD documentation in the EMR (50\% vs. $9 \%, \mathrm{P}<0.0001)$ were associated with increased renal referrals. In the posteGFR cohort, male gender ( $57 \%$ vs. $43 \%, \mathrm{P}=0.03$ ), diabetic status ( $57 \%$ vs. $44 \%, \mathrm{P}=0.03$ ), and CKD documentation in the EMR $(79 \%$ vs. $17 \%, \mathrm{P}<0.0001)$ were associated with increased referrals.

After adjusting for serum creatinine, a multivariable analysis of referral status revealed that only age $<70$ years was

Table 2 Baseline characteristics by eGFR and co-managed status

\begin{tabular}{|c|c|c|c|c|c|c|}
\hline & $\begin{array}{c}\text { Pre-eGFR/ PCP } \\
\text { managed } \\
(\mathrm{n}=222)\end{array}$ & $\begin{array}{c}\text { Post-eGFR/ PCP } \\
\text { managed } \\
(\mathrm{n}=159)\end{array}$ & $\begin{array}{c}\text { P-Value* (PCP } \\
\text { managed, } \\
\text { Pre vs. Post) }\end{array}$ & $\begin{array}{c}\text { Pre-eGFR/ } \\
\text { Co-managed } \\
(n=52)\end{array}$ & $\begin{array}{c}\text { Post-eGFR/ } \\
\text { Co-managed } \\
(\mathrm{n}=107)\end{array}$ & $\begin{array}{c}\text { P-Value* (Co- managed, } \\
\text { Pre vs. Post) }\end{array}$ \\
\hline Age (years) & $72.2(12.5)^{\dagger}$ & $69.6(13.0)$ & 0.05 & $63.3(16.1)^{\dagger}$ & $67.3(14.0)$ & 0.11 \\
\hline Female & $72.1 \%(160)$ & $62.9 \%(100)$ & 0.06 & $65.4 \%(34)$ & $57.9 \%(62)$ & 0.37 \\
\hline African-American & $22.5 \%(50)$ & $36.5 \%(58)$ & 0.0005 & $28.9 \%(15)$ & $41.1 \%(44)$ & 0.13 \\
\hline Diabetes & $30.2 \%(67)$ & $34.0 \%(54)$ & 0.25 & $38.5 \%(20)$ & $41.1 \%(44)$ & 0.75 \\
\hline Hypertension & $64.4 \%(143)$ & $75.5 \%(120)$ & 0.02 & $57.7 \%(30)$ & $86.0 \%(92)$ & $<0.0001$ \\
\hline \multicolumn{7}{|l|}{ Insurance Status } \\
\hline Private & $30.6 \%(68)$ & $45.3 \%(72)$ & 0.009 & $40.4 \%(21)$ & $48.6 \%(52)$ & 0.67 \\
\hline Medicare & $59.0 \%(131)$ & $49.1 \%(78)$ & & $46.2 \%(24)$ & $41.1 \%(44)$ & \\
\hline $\begin{array}{l}\text { Medical } \\
\text { Assistance }\end{array}$ & $5.0 \%(11)$ & $4.4 \%(7)$ & & $7.7 \%(4)$ & $7.5 \%(8)$ & \\
\hline Self-pay & $5.4 \%(12)$ & $1.3 \%(2)$ & & $5.8 \%(3)$ & $2.8 \%(3)$ & \\
\hline $\begin{array}{l}\text { eGFR } \\
\left(\mathrm{ml} / \mathrm{min} / 1.73 \mathrm{~m}^{2}\right)\end{array}$ & $37.2(6.3)^{* *}$ & $35.5(7.5)^{\ddagger}$ & 0.02 & $31.4(8.2)^{* *}$ & $31.0(7.6)^{\ddagger}$ & 0.78 \\
\hline Creatinine $(\mathrm{mg} / \mathrm{dl})$ & $1.71(0.42)^{* *}$ & $1.83(0.56)^{\ddagger}$ & 0.02 & $2.18(0.71)^{* *}$ & $2.19(0.86)^{\ddagger}$ & 0.94 \\
\hline
\end{tabular}

Continuous variables are presented as means with standard deviations. Categorical variables are expressed as percentages and frequencies.

*Students t-test, chi-square, or Fisher's exact test used as appropriate.

'pre-eGFR PCP managed versus pre-eGFR co-managed ( $P=0.0004)$.

** pre-eGFR PCP managed versus pre-eGFR co-managed $(P<0.0001)$.

fpost-eGFR PCP managed versus post-eGFR co-managed $(P<0.0001)$.

eGFR estimated glomerular filtration rate, PCP primary care physician. 


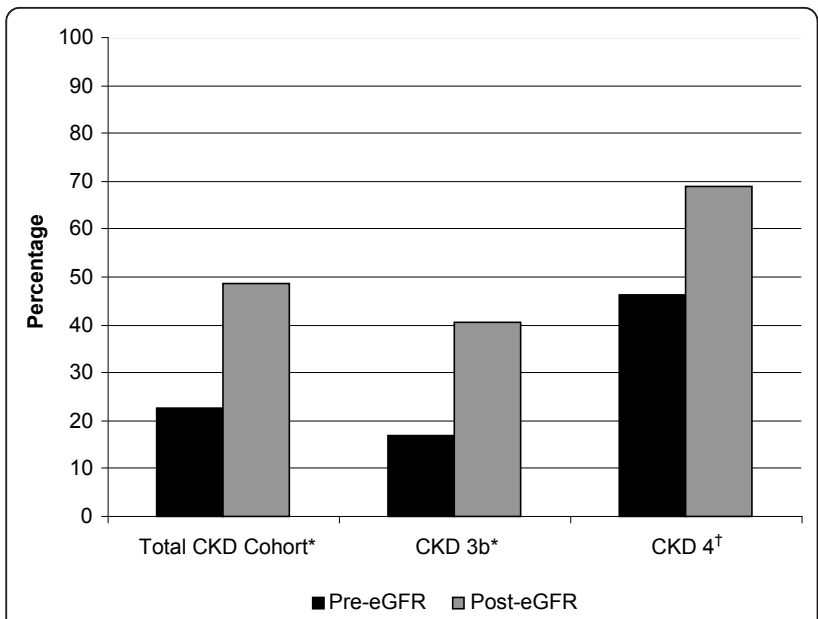

Figure 2 Co-management of CKD patients by eGFR cohort. PreeGFR cohort: $N=274$, Post-eGFR cohort: $N=266{ }^{*} P<0.0001,+P=0.01$ CKD chronic kidney disease, eGFR estimated glomerular filtration rate

associated with renal referrals in the pre-eGFR cohort while only diabetic status was borderline associated with referrals in the post-eGFR cohort (Table 3). CKD documentation was excluded from these models due to concern that nephrologists may have been responsible for documenting CKD in the EMR problem list after a patient was referred and evaluated.

\section{Trends in CKD care}

Overall, ACEI/ARB use, urinary albumin quantification, absence of both ACEI/ARB and urinary albumin quantification, and $\mathrm{Hgb}$ monitoring did not improve following eGFR reporting ( $58.4 \%$ vs. $58.6 \%, \mathrm{P}=0.9 ; 24.5 \%$ vs. $29.3 \%, \mathrm{P}=0.2 ; 37.6 \%$ vs. $32.7 \%, \mathrm{P}=0.2 ; 80.3 \%$ vs. $86.1 \%$, $\mathrm{P}=0.07$, respectively). However, NSAID avoidance and

Table 3 Multivariable associations with co-managed status after adjusting for serum creatinine

\begin{tabular}{lcc}
\hline & $\begin{array}{c}\text { Pre-eGFR } \\
\text { cohort* }^{*}\end{array}$ & $\begin{array}{c}\text { Post-eGFR } \\
\text { cohort }^{+}\end{array}$ \\
\hline $\begin{array}{c}\text { Adjusted OR } \\
(95 \% \mathrm{Cl})\end{array}$ & $\begin{array}{c}\text { Adjusted OR } \\
(95 \% \mathrm{Cl})\end{array}$ \\
\hline Age $(<70$ vs. $\geq 70$ years) & $\mathbf{2 . 7 4}(\mathbf{1 . 3 7 - 5 . 4 9 )}$ & $1.49(0.84-2.66)$ \\
\hline Sex (female vs. male) & $1.48(0.65-3.36)$ & $0.99(0.54-1.84)$ \\
\hline Race (AA vs. non-AA) & $1.05(0.49-2.27)$ & $0.85(0.47-1.55)$ \\
\hline $\begin{array}{l}\text { Insurance Status (private vs. non- } \\
\text { private**) }\end{array}$ & $1.81(0.88-3.76)$ & $1.16(0.65-2.07)$ \\
\hline $\begin{array}{l}\text { Diabetes (diabetic vs. non- } \\
\text { diabetic) }\end{array}$ & $1.61(0.81-3.19)$ & $1.77(1.00-3.14)$ \\
\hline
\end{tabular}

For each variable, the referent is the latter value listed within parentheses.

*Pre-eGFR cohort: $\mathrm{N}=274$;

${ }^{\dagger}$ Post-eGFR cohort: $\mathrm{N}=266$;

**Non-private insurance included Medicare, medical assistance/Medicaid, or self-pay.

eGFR estimated glomerular filtration rate, AA: African-American. phosphorus and PTH monitoring improved following routine eGFR reporting $(81.8 \%$ vs. $90.6 \%, \mathrm{P}=0.003$; $32.5 \%$ vs. $51.5 \%, \mathrm{P}<0.0001 ; 12.4 \%$ vs. $36.1 \%, \mathrm{P}<0.0001$, respectively). In sensitivity analyses examining patients with at least 2 or at least 3 serum creatinine values, findings did not substantially differ.

When examining PCP managed patients, there was no difference in CKD documentation, ACEI/ARB use, urinary albumin quantification, absence of ACEI/ARB and urinary albumin quantification, or Hgb monitoring following the use of eGFR reporting (Figure 3 and Figure 4). However, there was a borderline significant decrease in NSAID use and significant improvements in phosphorus and PTH monitoring following eGFR implementation (Figure 3 and Figure 4).

When examining co-managed patients, only PTH monitoring improved following eGFR reporting (Figure 3 and Figure 4). However, ACEI/ARB use in co-managed CKD 4 patients rose from $36.4 \%(\mathrm{n}=22)$ pre-eGFR to $60.5 \%$ $(\mathrm{n}=43)$ post-eGFR, although this was not statistically significant $(\mathrm{P}=0.07)$.

When comparing PCP managed and co-managed patients, NSAID use was higher and phosphorus and PTH monitoring were lower in PCP managed patients regardless of eGFR reporting (Figure 3 and Figure 4). In addition, in the post-eGFR cohort, PCP managed patients were less likely to obtain $\mathrm{Hgb}$ testing than comanaged patients (Figure 4).

\section{Discussion}

We observed a substantial increase in CKD patient comanagement following the use of routine eGFR reporting

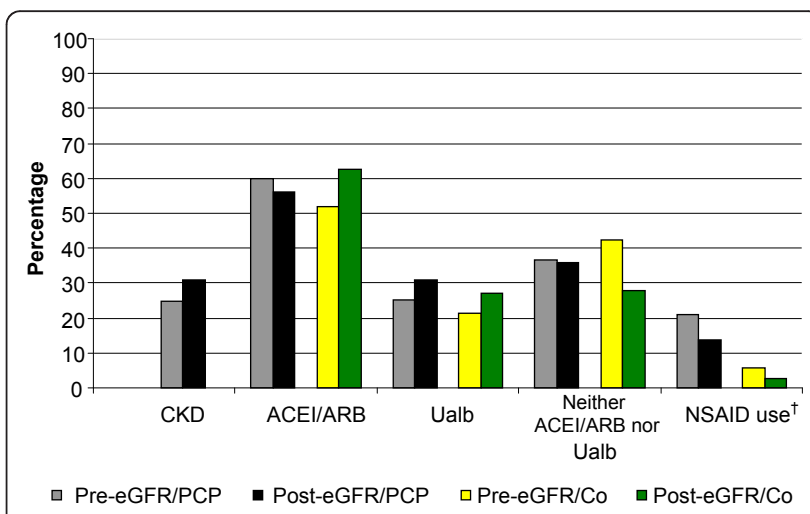

Figure 3 Quality of care delivered to CKD $3 \mathrm{~b}-4$ patients. Pre-eGFR cohort: $n=274$, Post-eGFR cohort: $n=266$. $†$ Pre-eGFR/PCP vs. Post-eGFR/PCP, $\mathrm{P}=0.07$; Pre-eGFR/PCP vs. Pre-eGFR/Co, $\mathrm{P}=0.01$; PosteGFR/ PCP vs. Post-eGFR/Co, P=0.003. CKD chronic kidney disease documentation, ACEI/ARB angiotensin converting enzyme inhibitor or angiotensin receptor blocker use, NSAID non-steroidal anti-inflammatory drug, Ualb quantitative urinary albumin testing, eGFR estimated glomerular filtration rate, PCP primary care physician managed, Co co-managed. 


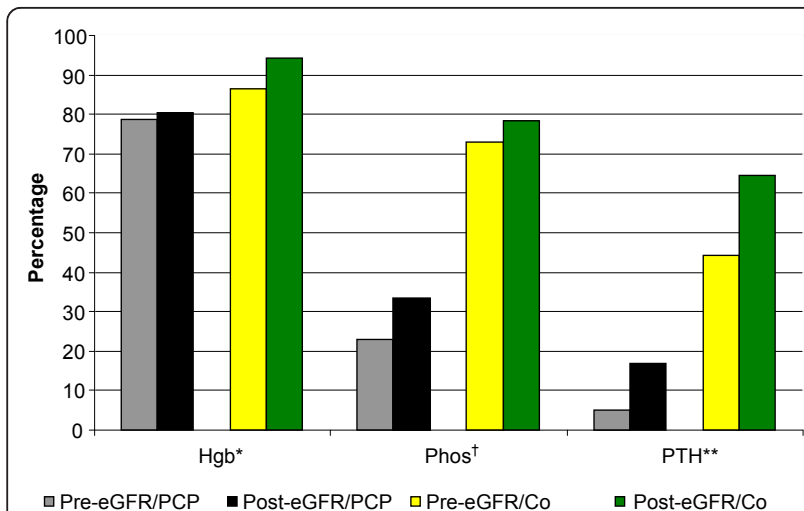

Figure 4 Laboratory processes of care for CKD 3b-4 patients. Pre-eGFR cohort: $n=274$, Post-eGFR cohort: $n=266$. * Post-eGFR/PCP vs. Post-eGFR/Co, $P=0.001$. + Pre-eGFR/PCP vs. Post-eGFR/PCP, $P=0.03$; Pre-eGFR/PCP vs. Pre-eGFR/Co, $P<0.0001$; PosteGFR/ PCP vs. Post-eGFR/Co, $P<0.0001$. **Pre-eGFR/PCP vs. Post-eGFR/PCP, $P=0.0001$; Pre-eGFR/Co vs. Post-eGFR/Co, $P=0.02$; PreeGFR/ PCP vs. Pre-eGFR/Co, P<0.0001; Post-eGFR/PCP vs. Post-eGFR/Co, P<0.0001. Hgb hemoglobin, Phos phosphorus, PTH parathyroid hormone, eGFR estimated glomerular filtration rate, PCP primary care physician managed, Co co-managed.

at an academic, hospital-based GIM clinic. At the conclusion of the respective study periods, nearly $50 \%$ of CKD $3 \mathrm{~b}-4$ patients were co-managed in the post-eGFR cohort compared to less than $25 \%$ of the pre-eGFR cohort. Significant increases in co-management were apparent in both CKD $3 \mathrm{~b}$ and CKD 4 patients. Following eGFR implementation, we also noted significant improvements in NSAID avoidance and mineral and bone disease related lab testing. However, ACEI/ARB use and urinary albumin quantification were not improved. While CKD care delivery to both PCP managed and co-managed patients remained suboptimal after eGFR reporting, comanaged patients were less likely to be on NSAIDs and more likely to have lab testing for complications of CKD.

Our observed increase in CKD patient co-management is similar to previous reports documenting increased nephrology referrals following implementation of routine eGFR reporting [8,26-28]. At our institution, moderate to advanced CKD patients previously had their kidney disease managed predominantly by their PCPs. Now, nearly half of all CKD $3 \mathrm{~b}-4$ patients are being co-managed. We noted both an increase in the prevalent proportion of CKD 3b-4 patients who were co-managed at the outset of each cohort as well as a significant increase in the proportion of patients who were newly referred during the study period. Together, these increases in renal referrals represent a substantial shift in CKD care by PCPs. Such shifts in PCP practice patterns may pose a logistical challenge to nephrology groups that are not equipped to deal with an influx of pre-dialysis CKD patients. Other centers have successfully adopted education and referral guideline programs to address this problem when present $[8,36]$. However, in localities where the increase in CKD patient referrals does not overwhelm capacity, this shift provides nephrologists with an opportunity to enhance the care of many CKD patients at an earlier stage of disease when treatment is more likely to prevent or delay cardiovascular disease and kidney failure [16,37-39].

Increased CKD co-management should lead to a greater emphasis on ensuring that treatment delivered by PCPs and nephrologists represents optimal care to reduce CKD morbidity and mortality. In addition to improved communication between PCPs and nephrologists, important goals in the management of CKD patients include blood pressure control, proteinuria suppression, ACEI/ARB therapy, cardiovascular disease risk factor modification, nephrotoxin avoidance, and treatment of complications from CKD (e.g., anemia) [7,40-42]. Although we did not examine clinical outcomes in this study, it is notable that ACEI/ $A R B$ use and lack of both albuminuria screening and ACEI/ARB therapy were unaffected by eGFR reporting. While a trend towards improved ACEI/ARB use was seen in co-managed CKD stage 4 patients, we suspect this was due to recent literature documenting the safety and efficacy of ACEI treatment in the setting of advanced CKD that was not available during the pre-eGFR cohort [43].

Our findings are similar to previous studies reporting minimal or no improvement in ACEI/ARB use following eGFR implementation [28,29]. In addition, approximately $1 / 3$ of our CKD cohort received neither an albuminuria screen nor ACEI/ARB therapy. Hence, providers did not know whether a significant number of their CKD patients possessed characteristics making them likely to benefit from ACEI/ARB therapy nor were they presumptively treating such patients. Although contraindications to ACEI/ARB therapy (e.g., angioedema, severe hyperkalemia) may have precluded their use, it should be noted that published rates of hyperkalemia in a recent nondialysis dependent CKD 3-5 cohort were approximately $5-12 \%$ [44] and the approximate rate of hyperkalemia (K > 5.5) for outpatients with CKD $3 \mathrm{~b}-5$ at our medical center is $17.1 \%$ in the previous 12 months (unpublished data). Hence, contraindications to ACEI/ARB are unlikely to explain these shortcomings in care fully.

While differences in CKD care between PCP managed and co-managed patients were apparent in the rates of NSAID avoidance and lab monitoring for potential complications of CKD, our findings generally confirm studies documenting sub-optimal CKD care among PCPs and nephrologists prior to eGFR reporting [10,33-35,45]. These results suggest that even with eGFR reporting, there remains substantial room for improvement in CKD care. Despite the marked increase in co-management, the majority of patients who were PCP managed at the outset of each cohort were not 
referred over the subsequent 8-months. This is similar to findings by Richards et al [8] who noted that despite the marked increase in renal referrals following eGFR implementation, only $33 \%$ of non-referred CKD 4-5 patients were referred in the following 12 months. This implies that although referrals have generally increased following eGFR reporting, a subset of patients may still be referred late. In our multivariable adjusted model of co-management status following eGFR reporting, only creatinine and diabetic status were associated with co-management. Given the documented increase in morbidity and mortality associated with late referrals [46], future studies should further examine patient characteristics that are associated with late referrals despite eGFR reporting.

Our findings should be interpreted in light of several limitations. First, we only examined patients with a documented creatinine value; however, some patients with CKD 3b-4 are unscreened and would be excluded from our analysis. Hence, the true rate of co-management and appropriate process of care outcomes is likely to be lower than reported here. Second, we required one eGFR $<45 \mathrm{ml} / \mathrm{min} / 1.73 \mathrm{~m}^{2}$ for inclusion in this study. However, the current National Kidney Foundation CKD definition requires a reduction in the GFR to $<60 \mathrm{ml} / \mathrm{min} / 1.73 \mathrm{~m}^{2}$ for at least 3 months. This potentially resulted in misclassification. However, the presence of two or more calculated eGFR values in nearly $80 \%$ and $95 \%$ of patients in the pre-eGFR and posteGFR cohorts respectively and the exclusion of all patients with a recent eGFR $\geq 60 \mathrm{ml} / \mathrm{min} / 1.73 \mathrm{~m}^{2}$ should have minimized this bias. Further, exclusion of patients with only 1 or 2 creatinine/eGFR measures did not significantly alter our findings. Third, serum creatinine assays were not standardized during the study period. Fourth, there were additional important process of care outcomes that we did not assess including appropriate lab monitoring following the initiation of ACEI/ ARB therapy. Fifth, improvements in care could be due to secular trends rather than eGFR implementation. For example, the recent interest in mineral and bone disease including vitamin D deficiency could explain the increased monitoring of phosphorus and PTH. In addition, there are other critical factors that may contribute to differences in the care delivered to CKD patients that were not controlled for in this study (e.g., patient comorbidities, underlying etiology of CKD). Finally, we studied a relatively small sample.

\section{Conclusions}

Following the implementation of routine eGFR reporting at an academic, outpatient primary care clinic, there has been a marked increase in the co-management of CKD $3 \mathrm{~b}-4$ patients and modest to moderate improvement in
CKD processes of care including NSAID avoidance and mineral and bone disease related lab testing. However, pre-dialysis CKD care remains suboptimal. While the best approach to improve clinical care for CKD patients is unproven, multiple interventions will likely be required to affect physician behavior [47]. Simple educational didactics, printed materials, and guideline development alone have generally failed to change practice patterns in a variety of medical settings [47]. Alternative approaches including combinations of audit and feedback, educational outreach, and clinical decision support systems have garnered increasing attention as potentially effective tools to improve physician performance [48-53].

This study identifies not only PCP care as suboptimal, but also reinforces prior documented shortcomings in nephrology care $[10,33-35,45]$. Such deficiencies despite the presence of CKD guidelines and eGFR reporting, especially in an academic setting where patient visits are generally longer and providers less hurried, highlight the need to employ a conceptual model of suboptimal CKD care delivery by providers to direct the evaluation of further interventions that may improve care delivery. Such a model should identify the numerous hurdles including perceptual and interpretive errors that may have been addressed by eGFR reporting. It should also identify additional barriers including gaps in knowledge and cognitive burdens not addressed by eGFR reporting but that will need to be overcome to incrementally enhance CKD care. Further studies are needed to explore the role of systematic interventions in addressing these barriers and optimizing the care of pre-dialysis CKD patients.

\section{Acknowledgements}

This work was supported by a National Kidney Foundation Clinical Research Fellowship and a Ruth L. Kirschstein National Research Service Award Institutional Research Training

Grants T32-DK061296 and Individual Postdoctoral Training Grant F32-

DK084676 (Abdel-Kader); however, the study design, data collection, analysis, interpretation, and manuscript preparation and submission were determined by the authors alone. This publication was also made possible by Grant Number UL1 RR024153 from the National Center for Research Resources (NCRR), a component of the National Institutes of Health ( $\mathrm{NIH})$, and $\mathrm{NIH}$ Roadmap for Medical Research. An abstract based on the content of this manuscript was presented as a poster at the November 2010 American Society of Nephrology annual meeting in Denver, USA.

\section{Author details}

${ }^{1}$ Renal-Electrolyte Division, University of Pittsburgh, Pittsburgh, USA. ${ }^{2}$ Department of General Internal Medicine, University of Pittsburgh, Pittsburgh, USA.

\section{Authors' contributions}

$\mathrm{KA}, \mathrm{GF}, \mathrm{J}, \mathrm{CM}$, and $\mathrm{MU}$ conceptualized the study. KA, GF, CM, and MU obtained funding. KA, GF, CG, CM, and MU acquired the data. KA, CG, CM, and $\mathrm{MU}$ analyzed the data. $\mathrm{KA}, \mathrm{GF}, \mathrm{J}, \mathrm{CG}, \mathrm{CM}$, and $\mathrm{MU}$ contributed to interpretation and manuscript preparation. All authors read and approved the final manuscript. 


\section{Competing interests}

The authors declare that they have no competing interests.

Received: 6 July 2010 Accepted: 15 March 2011

Published: 15 March 2011

\section{References}

1. Coresh J, Selvin E, Stevens LA, Manzi J, Kusek JW, Eggers P, Van Lente F, Levey AS: Prevalence of chronic kidney disease in the United States. Jama 2007, 298:2038-2047.

2. Flegal KM, Carroll MD, Ogden CL, Johnson CL: Prevalence and trends in obesity among US adults, 1999-2000. JAMA 2002, 288:1723-1727.

3. Hedley AA, Ogden $C L$, Johnson $C L$, Carroll MD, Curtin LR, Flegal KM: Prevalence of overweight and obesity among US children, adolescents, and adults, 1999-2002. JAMA 2004, 291:2847-2850.

4. Ogden $C L$, Carroll MD, Curtin LR, McDowell MA, Tabak CJ, Flegal KM: Prevalence of overweight and obesity in the United States, 1999-2004. JAMA 2006, 295:1549-1555.

5. Fields LE, Burt VL, Cutler JA, Hughes J, Roccella EJ, Sorlie P: The burden of adult hypertension in the United States 1999 to 2000: a rising tide. Hypertension 2004, 44:398-404.

6. Gregg EW, Cheng YJ, Narayan KM, Thompson TJ, Williamson DF: The relative contributions of different levels of overweight and obesity to the increased prevalence of diabetes in the United States: 1976-2004. Prev Med 2007, 45:348-352.

7. Johnson CA, Levey AS, Coresh J, Levin A, Lau J, Eknoyan G: Clinical practice guidelines for chronic kidney disease in adults: Part I. Definition, disease stages, evaluation, treatment, and risk factors. Am Fam Physician 2004, 70:869-876.

8. Richards N, Harris K, Whitfield M, O'Donoghue D, Lewis R, Mansell M, Thomas S, Townend J, Eames M, Marcelli D: The impact of populationbased identification of chronic kidney disease using estimated glomerular filtration rate (eGFR) reporting. Nephrol Dial Transplant 2008, 23:556-561.

9. Fox CH, Brooks A, Zayas LE, McClellan W, Murray B: Primary care physicians' knowledge and practice patterns in the treatment of chronic kidney disease: an Upstate New York Practice-based Research Network (UNYNET) study. J Am Board Fam Med 2006, 19:54-61.

10. Nissenson AR, Collins AJ, Hurley J, Petersen H, Pereira BJ, Steinberg EP: Opportunities for improving the care of patients with chronic renal insufficiency: current practice patterns. J Am Soc Nephrol 2001, 12:1713-1720.

11. Boulware LE, Troll MU, Jaar BG, Myers DI, Powe NR: Identification and referral of patients with progressive CKD: a national study. Am J Kidney Dis 2006, 48:192-204

12. Taal MW: Slowing the progression of adult chronic kidney disease: therapeutic advances. Drugs 2004, 64:2273-2289.

13. The Diabetes Control and Complications (DCCT) Research Group: Effect of intensive therapy on the development and progression of diabetic nephropathy in the Diabetes Control and Complications Trial. Kidney Int 1995, 47:1703-1720.

14. Brown WW, Peters RM, Ohmit SE, Keane WF, Collins A, Chen SC, King K, Klag MJ, Molony DA, Flack JM: Early detection of kidney disease in community settings: the Kidney Early Evaluation Program (KEEP). Am J Kidney Dis 2003, 42:22-35.

15. Stevens LA, Coresh J, Greene T, Levey AS: Assessing kidney functionmeasured and estimated glomerular filtration rate. N Engl J Med 2006, 354:2473-2483.

16. K/DOQI clinical practice guidelines for chronic kidney disease: evaluation, classification, and stratification. Am J Kidney Dis 2002, 39: S1-266.

17. Stevens LA, Coresh J, Feldman HI, Greene T, Lash JP, Nelson RG, Rahman M, Deysher AE, Zhang YL, Schmid CH, Levey AS: Evaluation of the modification of diet in renal disease study equation in a large diverse population. J Am Soc Nephrol 2007, 18:2749-2757.

18. Levey AS, Bosch JP, Lewis JB, Greene T, Rogers N, Roth D: A more accurate method to estimate glomerular filtration rate from serum creatinine: a new prediction equation. Modification of Diet in Renal Disease Study Group. Ann Intern Med 1999, 130:461-470.

19. Levey AS, Coresh J, Greene T, Marsh J, Stevens LA, Kusek JW, Van Lente F: Expressing the Modification of Diet in Renal Disease Study equation for estimating glomerular filtration rate with standardized serum creatinine values. Clin Chem 2007, 53:766-772.

20. Levey AS, Coresh J, Greene T, Stevens LA, Zhang YL, Hendriksen S, Kusek JW, Van Lente F: Using standardized serum creatinine values in the modification of diet in renal disease study equation for estimating glomerular filtration rate. Ann Intern Med 2006, 145:247-254.

21. Accetta NA, Gladstone EH, DiSogra C, Wright EC, Briggs M, Narva AS: Prevalence of estimated GFR reporting among US clinical laboratories. Am J Kidney Dis 2008, 52:778-787.

22. Stevens LA, Levey AS: Impact of reporting estimated glomerular filtration rate: it's not just about us. Kidney Int 2009, 76:245-247.

23. Anavekar N, Bais R, Carney S, Davidson J, Eris J, Gallagher M, Johnson D, Jones G, Sikaris K, Lonergan M, et al: Chronic kidney disease and automatic reporting of estimated glomerular filtration rate: a position statement. Clin Biochem Rev 2005, 26:81-86.

24. Mathew TH: Chronic kidney disease and automatic reporting of estimated glomerular filtration rate: a position statement. Med J Aust 2005, 183:138-141.

25. Miller WG: Reporting estimated GFR: a laboratory perspective. Am J Kidney Dis 2008, 52:645-648.

26. Noble E, Johnson DW, Gray N, Hollett P, Hawley CM, Campbell SB, Mudge DW, Isbel NM: The impact of automated eGFR reporting and education on nephrology service referrals. Nephrol Dial Transplant 2008, 23:3845-3850.

27. Jain AK, McLeod I, Huo C, Cuerden MS, Akbari A, Tonelli M, van Walraven C, Quinn RR, Hemmelgarn B, Oliver MJ, et al: When laboratories report estimated glomerular filtration rates in addition to serum creatinines, nephrology consults increase. Kidney Int 2009, 76:318-323.

28. Hemmelgarn BR, Zhang J, Manns BJ, James MT, Quinn RR, Ravani P, Klarenbach SW, Culleton BF, Krause R, Thorlacius L, et al: Nephrology visits and health care resource use before and after reporting estimated glomerular filtration rate. JAMA 303:1151-1158.

29. Wyatt C, Konduri V, Eng J, Rohatgi R: Reporting of estimated GFR in the primary care clinic. Am J Kidney Dis 2007, 49:634-641.

30. Quartarolo JM, Thoelke M, Schafers SJ: Reporting of estimated glomerular filtration rate: effect on physician recognition of chronic kidney disease and prescribing practices for elderly hospitalized patients. J Hosp Med 2007, 2:74-78.

31. Thilly N, Boini S, Kessler M, Briancon S, Frimat L: Chronic kidney disease: appropriateness of therapeutic management and associated factors in the AVENIR study. J Eval Clin Pract 2009, 15:121-128.

32. Thilly N, Boini S, Kessler M, Briancon S, Frimat L: Management and control of hypertension and proteinuria in patients with advanced chronic kidney disease under nephrologist care or not: data from the AVENIR study (AVantagE de la Nephroprotection dans I'Insuffisance Renale). Nephrol Dial Transplant 2009, 24:934-939.

33. Bailie GR, Eisele G, Liu L, Roys E, Kiser M, Finkelstein F, Wolfe R, Port F, Burrows-Hudson S, Saran R: Patterns of medication use in the RRI-CKD study: focus on medications with cardiovascular effects. Nephrol Dial Transplant 2005, 20:1110-1115.

34. Curtis BM, Barrett BJ, Djurdjev O, Singer J, Levin A: Evaluation and treatment of CKD patients before and at their first nephrologist encounter in Canada. Am J Kidney Dis 2007, 50:733-742.

35. Kausz AT, Khan SS, Abichandani R, Kazmi WH, Obrador GT, Ruthazer R, Pereira BJ: Management of patients with chronic renal insufficiency in the Northeastern United States. J Am Soc Nephrol 2001, 12:1501-1507.

36. Akbari A, Swedko PJ, Clark HD, Hogg W, Lemelin J, Magner P, Moore L, Ooi D: Detection of chronic kidney disease with laboratory reporting of estimated glomerular filtration rate and an educational program. Arch Intern Med 2004, 164:1788-1792.

37. Ghossein C, Serrano A, Rammohan M, Batlle D: The role of comprehensive renal clinic in chronic kidney disease stabilization and management: The Northwestern experience. Semin Nephrol 2002, 22:526-532.

38. Jones $C$, Roderick P, Harris $S$, Rogerson M: Decline in kidney function before and after nephrology referral and the effect on survival in moderate to advanced chronic kidney disease. Nephrol Dial Transplant 2006, 21:2133-2143.

39. Orlando LA, Owen WF, Matchar DB: Relationship between nephrologist care and progression of chronic kidney disease. N C Med J 2007, 68:9-16.

40. Jafar TH, Stark PC, Schmid CH, Landa M, Maschio G, de Jong PE, de Zeeuw D, Shahinfar S, Toto R, Levey AS: Progression of chronic kidney 
disease: the role of blood pressure control, proteinuria, and angiotensinconverting enzyme inhibition: a patient-level meta-analysis. Ann Intern Med 2003, 139:244-252.

41. Sarnak MJ, Greene T, Wang X, Beck G, Kusek JW, Collins AJ, Levey AS: The effect of a lower target blood pressure on the progression of kidney disease: long-term follow-up of the modification of diet in renal disease study. Ann Intern Med 2005, 142:342-351.

42. Meguid El Nahas A, Bello AK: Chronic kidney disease: the global challenge. Lancet 2005, 365:331-340.

43. Hou FF, Zhang X, Zhang GH, Xie D, Chen PY, Zhang WR, Jiang JP, Liang M, Wang GB, Liu ZR, Geng RW: Efficacy and safety of benazepril for advanced chronic renal insufficiency. N Engl J Med 2006, 354:131-140.

44. Korgaonkar S, Tilea A, Gillespie BW, Kiser M, Eisele G, Finkelstein F, Kotanko P, Pitt B, Saran R: Serum potassium and outcomes in CKD: insights from the RRI-CKD cohort study. Clin J Am Soc Nephrol 5:762-769.

45. Philipneri MD, Rocca Rey LA, Schnitzler MA, Abbott KC, Brennan DC, Takemoto SK, Buchanan PM, Burroughs TE, Willoughby LM, Lentine KL: Delivery patterns of recommended chronic kidney disease care in clinical practice: administrative claims-based analysis and systematic literature review. Clin Exp Nephrol 2008, 12:41-52.

46. Chan MR, Dall AT, Fletcher KE, Lu N, Trivedi H: Outcomes in patients with chronic kidney disease referred late to nephrologists: a meta-analysis. Am J Med 2007, 120:1063-1070

47. Bero LA, Grilli R, Grimshaw JM, Harvey E, Oxman AD, Thomson MA: Closing the gap between research and practice: an overview of systematic reviews of interventions to promote the implementation of research findings. The Cochrane Effective Practice and Organization of Care Review Group. BMJ 1998, 317:465-468.

48. Kawamoto K, Houlihan CA, Balas EA, Lobach DF: Improving clinical practice using clinical decision support systems: a systematic review of trials to identify features critical to success. BMJ 2005, 330:765.

49. Smith WR: Evidence for the effectiveness of techniques To change physician behavior. Chest 2000, 118:8S-17S.

50. Shea S, DuMouchel W, Bahamonde L: A meta-analysis of 16 randomized controlled trials to evaluate computer-based clinical reminder systems for preventive care in the ambulatory setting. J Am Med Inform Assoc 1996, 3:399-409.

51. Garg AX, Adhikari NK, McDonald H, Rosas-Arellano MP, Devereaux PJ, Beyene J, Sam J, Haynes RB: Effects of computerized clinical decision support systems on practitioner performance and patient outcomes: a systematic review. Jama 2005, 293:1223-1238.

52. Chertow GM, Lee J, Kuperman GJ, Burdick E, Horsky J, Seger DL, Lee R, Mekala A, Song J, Komaroff AL, Bates DW: Guided medication dosing for inpatients with renal insufficiency. JAMA 2001, 286:2839-2844.

53. Balas EA, Weingarten S, Garb CT, Blumenthal D, Boren SA, Brown GD: Improving preventive care by prompting physicians. Arch Intern Med 2000, 160:301-308

\section{Pre-publication history}

The pre-publication history for this paper can be accessed here: http://www.biomedcentral.com/1471-2369/12/12/prepub

doi:10.1186/1471-2369-12-12

Cite this article as: Abdel-Kader et al:: Characterizing pre-dialysis care in the era of eGFR reporting: a cohort study. BMC Nephrology 2011 12:12.

\section{Submit your next manuscript to BioMed Central and take full advantage of:}

- Convenient online submission

- Thorough peer review

- No space constraints or color figure charges

- Immediate publication on acceptance

- Inclusion in PubMed, CAS, Scopus and Google Scholar

- Research which is freely available for redistribution

Submit your manuscript at www.biomedcentral.com/submit
Biomed Central 